\title{
A PEREGRINAÇÃO DO SANTO VIVOE O SER DE DEUS EM FEUERBACH
}

\author{
Marcelo João Soares de Oliveira ${ }^{1}$
}

\section{RESUMO:}

Este artigo é fruto de uma pesquisa teórica sobre a peregrinação do santo vivo e suas repercussões na construção das subjetividades, considerando os referenciais das ciências da religião e da crítica feuerbachiana sobre a religião. Em seus estudos, Ludwig Feuerbach tem apresentado grande preocupação com o fenômeno religioso. Ele pensa o problema de Deus como sendo o próprio homem exteriorizado e é através da religião que o ser humano se expressa.O fenômeno do santo vivo, é a linguagem própria de o peregrino expressar-se e revelar-se e de comunicar o que há de mais profundo em si mesmo, quando ele se

relaciona com o santo vivo, descobre-se a si mesmo, vê a sua própria essência e não um personagem reconhecido por alguma instituição. Assim, o peregrino transforma a essência humana em santo vivo. A peregrinação em busca do santo vivo deve ser livre e sem interesse, não é obrigação, mas identificação.A partir da contextualização da peregrinação e seus significados para o peregrinose percebe que as peregrinações não são todas iguais, mas, escondem enigmas que apontam para a diversidade de sentidos, de gestos e de promessas dos peregrinos. O peregrino faz promessa não porque necessita, mas porque quer. Além disso, elas não podem ser coarctadas, restritassomente aocampo religioso, seu sentido ecoa nos aspectos sociais e políticos. Os clamores dos peregrinos revestidos de sentido religioso canalizam anseios de reconhecimento social. Assim, neste artigo pretendo pensar a peregrinação do santo vivoe a projeção de qualidades e desejosdos peregrinos refletindo algumas ideias de Feuerbach.

Palavras-chave: Santo vivo; Peregrinação; Ex-voto; Feuerbach.

\begin{abstract}
:
This article is the result of theoretical research on the pilgrimage of the living saint and its repercussions in the construction of subjectivities, considering the reference of the religious sciences and Feuerbach's critique of religion. In their studies, Ludwig Feuerbach has shown great concern for the religious phenomenon. He thinks the problem of God as the man himself externalized and it is through religion that the human being is expressed. The phenomenon of living saint, is the very language of the pilgrim express themselves and prove and communicate what is deepest in itself, when it relates to the living saint, finds himself, see its very essence and not a character recognized by an institution. Thus, the pilgrim turns the human essence in living saint. The pilgrimage in search of the living saint should be free and without interest, it is not required, but identification. From the context of the pilgrimage and their meanings for the pilgrim realizes that pilgrimages are not all alike, but hide puzzles that point to the diversity of meanings, gestures and promises of pilgrims. The pilgrim does not promise because it needs, but because he wants to. In addition, they cannot be impeded in, restricted only to the religious field, its echoes felt in social and political aspects. The cries of coated pilgrims from religious sense channel longings for social recognition. So in this article I intend to think about the pilgrimage of the living saint and the projection of qualities and desires of pilgrims reflecting some ideas of Feuerbach.
\end{abstract}

Keywords: live Holy; pilgrimage; Ex-voto; Feuerbach.

\footnotetext{
${ }^{1}$ Doutor em Ciências da Religião pela PUC-SP. E-mail: marcelojsoliveira@hotmail.com
} 


\section{Introdução}

A peregrinação tem revelado enigmas que podem ser intuídos nos gestos e expressividades dos peregrinos ${ }^{3}$, o que coloca um novo desafio a ser alcançado pelos pesquisadores que se sujeitam a investigar as peregrinações no contexto da religiosidade popular. O surgimento de novas formas de peregrinação e de comunicação com o sagrado integra um conjunto de procedimentos que o pesquisador precisa analisar, pois, sem uma visão apropriada de certas atitudes que tentam transmitir algo e forma expressiva, será difícil entender as dinâmicas e rituais presentes no contexto das peregrinações e refletir sobre as expressividades dos peregrinos no espaço sagrado em que atuam.

Nesse sentido, em se tratando das peregrinações de Canindé ${ }^{4}$, os peregrinos procuram em suas jornadas o santo Francisco de Assis falecido em 1226 que, segundo os peregrinantes, se encontra vivo e escondido na cidade. Esse enigma é o elemento fundamental. Assim, pensar esse tema pressupõe assumir as implicações de uma "outra lógica".

Em Canindé, a tradição popular registra que São Francisco estaria vivo, apenas escondido em algum lugar da cidade, crença embasada em curioso fato. Em um determinado convento da cidade, vários peregrinos passaram a fazer longas filas para olhar pela fechadura da porta principal, com a convicção de que veriam o santo do outro lado. Os frades, a fim de impedir essa manifestação, tamparam a fechadura. Em resposta, os peregrinantes passaram a procurar o santo vivo, olhando pelas frestas da tampa protetora da pia do santuário e de outras aberturas igualmente estreitas. Mas o que o peregrino vê pelas frestas que os religiosos não conseguem ver? Quem é ou o que é na verdade o santo vivo?

O santo vivo, é uma forma de falar de si e não de outrem, quando o peregrino se relaciona com o santo vivo, descobre-se a si mesmo, vê a sua própria essência e não um

\footnotetext{
${ }^{3}$ Antes de tudo, vale lembra que a palavra peregrino vem de per, através de e ager, território, campo, de onde provém pereger, viajante, e peregre, estrangeiro, daí o termo peregrinus, estrangeiro, de fora.A peregrinação é uma viagem de fora para dentro. Um viajar de si para si. É a vida enquanto caminho. É voltar-se para si mesmo. Por outro lado, o termo romaria se refere aquele que se dirige, por motivo religioso, a Roma, trata-se de uma jornada a um lugar sagrado, igreja ou festa devocional e popular. A romaria é uma saída de si, do cotidiano para um espaço sagrado. É uma viagem de dentro para fora.

${ }^{4}$ Canindé possui um dos mais conhecidos centros de peregrinação e espaços sagrados do Brasil: o Santuário de São Francisco das Chagas, situado na cidade de Canindé, estado do Ceará, região Nordeste. Busca-se compreender o fenômeno religioso a partir de um conjunto de traços característicos do ambiente e do peregrino, o que dá origem a uma imagem marcada pelo mistério.
}

\begin{tabular}{|l|l|l|l|l|}
\hline Ronista Cialeatus & Ano 2 & n. 6 & Janeiro - Agosto 2015 & p. 138-149 \\
\hline
\end{tabular}


personagem reconhecido por alguma instituição. Não se aproxima de alguém canonizado ou cultuado historicamente, mas volta-se para seu ser, acredita em seu próprio potencial, supervive independentemente das instituições e resgata suas forças e valores, nome e família, símbolos e espaço sagrado, o arcabouço de sua identidade. A busca do santo vivo, significa o método próprio de revelar-se, de manifestar-se em busca da construção de sentido. Quanto mais ele fala do santo vivo e escondido, mais se torna visível quem ele é.

Por outro lado, existe a experiência religiosa marcada pelo santo morto que está relacionada a instituição e tudoque se relaciona com o santo sem sangue, ou seja , imagens, objetos litúrgicos, liturgia, ritos oficiais. É vista e analisada com um olhar bastante institucional ou profissional. É a prática religiosa marcadamente técnica e mecânica, fria e distante da vida daspessoas, dos problemas. Dessa forma, operegrino, mesmo assíduo nas festividades religiosas e praticante de devoções, independentemente da religião oficial,se não peregrinar de si para si, continua se relacionando com um personagemconstruto histórico, santo ou eleito da instituição.

Para conseguira libertação do santo morto, o peregrino procura dar visibilidade ao santo vivo, que é uma forma de criticar as instituições sociais, políticas e religiosas. No aspecto religioso, o peregrino se organiza de forma dinâmica e de modo sistemático, propondo o seguinte:

1. acatar em silêncio os procedimentos oficiais da Igreja;

2. acreditar nos detentores do sagrado da religião oficial;

3. respeitar os sacramentos.

Apesar de acatar em silêncio os procedimentos oficiais, o peregrino, ao perceber que a Igreja possui mais autoridade e alcance político que ele, tenta participar das celebrações e de seus momentos litúrgicos, mas de forma secundária. Ele não prioriza as confissões ou o recebimento da hóstia, preferindo identificar-se com o santo, beijá-lo, tocá-lo e vestir-se igual a ele, prestar suas homenagens, muitas vezes, durante a missa, dentro ou fora da igreja.

O peregrino acredita com restrição na mediação dos padres, religiosos, freiras, ministros e isso explica porque ele não quer assumir grandes compromissos. Ele participa de modo selecionado de momentos litúrgicos. Muitas vezes, acrescenta algo de

\begin{tabular}{|l|l|l|l|l|}
\hline Q Rovista Dialectus & Ano 2 & n. 6 & Janeiro - Agosto 2015 & p. 138-149 \\
\hline
\end{tabular}


novo, com autoridade própria, benze, reza, cura, ensina, profetiza, demonstrando claramente o não envolvimento direto com os detentores dos poderes religiosos da Instituição.

O peregrino, quando participa dos sacramentos oficiais, procura não se envolver completamente e não seguir todas as linhas propostas. Ele costuma seguir seu próprio caminho, o do "meio", tirando o que lhe interessa e realizando como the apraz.

Muitos peregrinos, por exemplo, não celebram o sacramento do matrimônio, pois o valor e a interpretação atribuídos pelo fiel a esse rito são diferentes da religião oficial. Eles costumam ressignificar, modificar e até criar novos rituais e sacramentos. Assim, ritualizam seus encontros e fazem memórias sagradas deles, elaboram símbolos e experimentos que expõem suas conquistas, como é o caso dos ex-votos.

\section{Ex-voto}

No aspecto político, os peregrinos procuram manifestar suas críticas através dos ex-votos ${ }^{5}$ que são a priori artefatos como maquetes de partes do corpo, retratos, fardamentos, pinturas, cachos de cabelo, imagens, entre outros, em sinal de reconhecimento e gratidão pela graça alcançada. Mas os ex-votos permitem entrever outra realidade: as moléstias são um modo simbólico de dizer como está a vida do peregrino, no que tange a saúde, emprego, paz, moradia, inteireza etc. Não somente fala de "milagre" e "graça alcançados", mas, da falta de assistência dos políticos e profissionais de saúde a comunidade carente. Contudo, os peregrinos ao exibirem seus ex-votos denunciam a forma de governo e mostram que conseguiram seus êxitos com seus esforços, ou seja, com a prática de seus rituais sem o apoio das instituições.

\footnotetext{
${ }^{1}$ A palavra ex-voto é uma abreviação latina de ex-voto suscepto, que significa "o voto alcançado". O termo designa pinturas, estatuetas e variados objetos ofertados aos santos ou divindades como forma de agradecimento por um pedido ou voto atendido. Diz respeito a uma expressão artístico-religiosa que se relaciona intimamente à arte religiosa e popular. Vários são os motivos para serem confeccionados os exvotos: pedido de proteção, cura de doenças, superação de desilusão amorosa, obtenção de moradia ou de emprego, aprovação nos estudos. O objeto do ex-voto possui diversas formas e materiais: maquetes, placas, roupas, carteiras de trabalho, cabelos, fotografias, réplicas da parte do corpo afetada por doenças (órgãos sexuais, braços, pernas, mãos, coração, cabeça) feitas em barro, gesso, madeira, cera, tecido, papelão, conhecidos como "ex-votos anatômicos". As peças fragmentadas dos corpos em forma de exvotos podem significar também, de maneira simbólica, como está a vida daqueles que ofertam tais objetos, ou mesmo, representar a memória da experiência do peregrino com o santo ou divindade. Sua origem é incerta, fala-se de fontes antigas entre os fenícios. Mais detalhes a este respeito podem ser encontrados em: Oliveira (2003). Sobre outros aspectos importantes do ex-voto, consultar Silva (1981), Castro (1994) e Scarano (2004).
}

\begin{tabular}{|l|l|l|l|l|}
\hline Revista Cialectus & Ano 2 & n. 6 & Janeiro - Agosto 2015 & p. 138-149 \\
\hline
\end{tabular}


A denúncia, relaciona-se com as diversas situações da vida cotidiana do peregrino que relatam, durante os rituais, desejos, sonhos, frustrações, angústias. Os resultados são refletidos nos ex-votos e atribuídos ao santo vivo, que além da influência política e religiosa, assume papel importante no imaginário e na realidade vivida do peregrino. Esse santo difere do que é apresentado pelas instituições, pois ele é reconhecido não pelos documentos e pesquisas, mas pela maneira genuína e descomplicada com que o peregrino chega até ele, ou seja, por meio da gratuidade, dos ex-votos da vida.

Em Canindé, verifica-se que o maior sentido da vida do peregrino, sentimento provocante e motivador de suas esperanças em seguimento até o santuário, é o conhecimento de si revelado nos ex-votos. Por meio deles, vê-se o peregrino no seu cotidiano. Consegue-se observar por meio dos sinais, os mais variados, diversos dadose elementos sobre um desconhecido, desde operfil físico, além de outros aspectos, tais como: vestuário, escolaridade, condições de higiene, tipo de cabelo, forma de calçados, cor da veste, uso de relógio, maneira de falar, caráter geral etc. "Em síntese, cada pessoa está vivendo dentro de padrões codificados a denotar e a informar sobre o meio e a classe social, modo de pensar, profissão e família e procedimento" ${ }^{\text {. }}$.

Os ex-votos amontanhados e expostos no salão de festas refletem aindaas ameaças, mutilações, agressões e sofrimentos, mas, também, é um grito em silêncio de denúncia contundente das condições da vida esquecida pelas instituições e pelos políticos. Para compreender essa denúncia, é preciso perceber as crenças, audácias, vontades e condutas dos peregrinos por meio dos ex-votos e analisá-los como um processo múltiplo, que abrange diferentes dimensões (religiosas, sociais, econômicas, culturais, saúde) e movimenta a vida social dos peregrinos em todo seu contexto.

Assim, nos ex-votos, demonstra-se a resposta aos problemas pessoais e de agrupamento em favor do peregrino, atribuída ao santo vivo, mais eficiente do que a assistência prestada pelas instituições sociais.Todos esses milhares de ex- votos simbolizam o Santo vivo, acolhedor do corpo chagado e amputado dos peregrinos. Ele está aí, visível, palpável neste amontoado de peças, mas unido ao peregrino.

Através da peregrinação do santo vivo, o peregrino tenta permanecer dentro de si mesmo, responder ao quem sou eu neste novo mundo distante do seu. Ele parece perder

\footnotetext{
${ }^{6}$ Para aprofundar esse tema dos ex-votos, ver: Oliveira (2007).
}

\begin{tabular}{|c|c|c|c|c|}
\hline Revista Dialectus & Ano 2 & n. 6 & Janeiro - Agosto 2015 & p. $138-149$ \\
\hline
\end{tabular}


a noção de tempo e espaço, de identidade e sentido, num lugar que não the cabe. Com isso surgem dúvidas e tensões que ele tenta superar através do peregrinar angustiante. Essas dúvidas provocam desarmonia e são, por sua vez, atentadas pelas instituições e representações sociais, políticas e religiosas. Elas são o mundo real, o outro, o diferente, o que invade e possui aquele que faz o caminho, retirando de dentro de cada um os elementos que constituem o arcabouço da identidade: as crenças, os valores, as riquezas. O mundo real é um sofrimento, onde se promove perdas e vazios, dispersões e confrontos, uma ameaça a vida do peregrino. Insurge então uma inversão para não cessar seus passos: sair deste mundo real e entrar no imaginário ${ }^{7}$.

A definição deimaginário difere do que normalmente se pensa no meio popular. $\mathrm{Na}$ concepção popular não há diferença entre imaginário e imaginação. $\mathrm{O}$ termo imaginação carrega a ideia de irrealidade, embuste, mentira, exagero, excesso. Essas ideias aparecem no pensamento de Feuerbach quando trata do homem religioso. Ele pensa o aspecto subjetivo da pessoa, como algo não resolvido do próprio homem religioso. Opoder da imaginação age no mundo subjetivo, dando origem a um universo objetivo. Insurge,então, uma verdade da imaginação, proporcionandoresultados que não são reais. Assim, a imaginação é concebida como realidade. A imaginação é propícia a erros por ser considerada a principal forma de conhecimento, ela altera a realidade e conduz a pessoa ao mundo da fantasia.

Por outro lado, pela imaginação, a pessoa pode relacionar-se com o ausente e com o inexistente, isso pode tornar-se possível o tempo futuro e o campo dos possíveis, como por exemplo, imaginar uma obra de arte ou um quadro a ser pintado é relacionarse com o mesmo em forma de imagem. A obra ainda não foi concluída nem começada, mas é uma obra possível.

O imaginário dos peregrinos os transporta a uma dimensãoparadoxal presente / ausente, ou seja, patenteem seus motivos ou razões radicais, para dirigir-se à perspectiva sonhada, porém distante. Em outras palavras, comunicam um futuropossível, remetem a uma utopia quena experiência dos peregrinos permite sintonizá-loscom a realidade inexorável e também com o devaneio, possibilitando transformar-lhes a existência martirizada e sofrida.

\footnotetext{
${ }^{7}$ Devemos compreender aqui o conceito de Imaginário diferente do que pensa o senso comum que costuma confundir este termo com a palavra imaginação. Por imaginário deve-se entender o sentido da capacidade que a pessoa tem de representar algo com recurso de associação de imagens que lhe atribuem um sentido. Por isso, se fala em Imaginário Pessoal e Social.
}

\begin{tabular}{|c|c|c|c|c|}
\hline Renista Dialectus & Ano 2 & n. 6 & Janeiro - Agosto 2015 & p. $138-149$ \\
\hline
\end{tabular}


O que varia nesse aspecto utópico é o conteúdo, sua maneira de imaginá-lo realizado. Nesse sentido, a superação do peregrino reflete a utopia que alimenta a práxis de muitos peregrinantes no que diz respeito a sua profunda libertação, expressa através do desejo de aquisição de casa própria, emprego, partilha, cura de doença grave, relacionamento afetivo. Por isso, as necessidades dos peregrinos, ou seja, seu sonho de ir mais além, “[...] ainda sem-lugar, exerce função crítica ao presente existente [...]" (LIBÂNEO, 1989, p. 18). É aí que intervêm os modos próprios de cada tipo de peregrinação, bem como os valores que recolhem como símbolos nos lugares sagrados em que são aplicados para a formulação de utopias.

De acordo com (RUSCHEINSKY, 1988 apud LIBÂNEO, 1989, p. 173), a utopia “[...] desempenha um papel fundamental na formação ideológica das classes subalternas, porque impulsiona para além daquilo que é possível na atual correlação de forças sociais [...].". Ela reflete uma sociedade baseada na justiça e fraternidade, num sonho de superação do qual, apesar de não ser visualizado na associação vigente, há indícios categóricos na prática de muitos peregrinos. Nesse contexto, a peregrinação desponta como ensaio da possibilidade de efetivação desse projeto utópico. Sua relação harmônica, seus encontros, sua organização e práxis desfraldam referências que indicam de forma simbólica a concretização da utopia mediante o acontecer antevisto, incipiente e limitado de tais promessas(LIBÂNEO, 1989).

A superação que se manifesta em cada peregrino exige responsabilidade que cada um descobre a partir da peregrinação, podendo interpretá-la segundo suas capacidades e intimidades com o santo vivo. Mas, esse procedimento exige dos peregrinos algumas tomadas de decisões que podem causar dificuldades e tensões com a Igreja oficial.

A relação entre os representantes oficiais da Igreja e os peregrinos se mostra de forma ambivalente, refletindo dificuldades e tensões, pois a primeira pretende conter o ritmo dos passos dos peregrinos e indicar o caminho através da catequese e da orientação religiosa e a outra pretende dinamizar com rituais próprios a construção de sentido.

Para Feuerbach em sua obra "A essência do cristianismo"a experiência do homem religioso em si ou a própria religião não propicia a devida importância a vida no estado presente, aplica toda esperança de conquistas no céu. Assim, todas as necessidades humanas e conquistas devem ser lançadas para o outro mundo. Para ele o

\begin{tabular}{|l|l|l|l|l|}
\hline Q Rovista Qialectus & Ano 2 & n. 6 & Janeiro - Agosto 2015 & p. 138-149 \\
\hline
\end{tabular}


homem religioso não se envolve com as transformações sociais, com as injustiças, sofrimento e miséria deste mundo, ou seja, a experiência religiosa se conforma com toda essa situação e projeta a felicidade no além.Sua estratégia filosófica é de refletir a questão religiosa a partir de ideias antropológicas, colocando a religião como representação dos desejos do homem.

$\mathrm{Na}$ realidade, ele acredita que a religião é a essência do ser humano, das suas qualidades projetadas para fora de si. É a essência objetivada do ser humano.Feuerbach diz a esse respeito:

Como o homem pensar, como for intencionado, assim é o seu Deus: quanto valor tem o homem, tanto valor e não mais tem o seu Deus. A consciência de Deus é a consciência que o homem tem de si mesmo, o conhecimento de Deus é o conhecimento que o homem tem de si mesmo (FEUERBACH, 1988, p. 55).

Para Feuerbach, o Deus do ser humano é a afirmação do homem, é a expressão fiel do próprio ser humano. Ele aponta o homem como ser concreto, natural e social. Nesse sentido, Deus e o homem são idênticos ${ }^{8}$. Para o homem recuperar sua essência perdida é necessário redescobrir sua dignidade ${ }^{9}$. É necessário dar um novo ponto de partida a todo o processo de compreensão de Deus. O ponto de partida é o próprio homem e não Deus.

O homem precisa viver não apenas como uma simples aquisição intelectual, mas viver uma dimensão construtiva e regular através de críticas constantes ativa do próprio ser humano a ponto de determinar a sua própria natureza. É importante fazer uma busca pelas raízes da essência humana na procura da verdade autêntica. É preciso fazer uma transmutação de valores.Assim, Feuerbach entende que a teologia é a antropologia porque todos os atributos de Deus são predicados do homem. Para que o homem possa se afirmar, é necessário negar a Deus da religião. Assim, ele trata do problema da morte de Deus que embora seja metafísico, carrega uma base antropológica. A base está nas questões que são abordadas, são indagações humanas e dizem respeito as situações da realidade vivida.

O problema da morte de Deus não visa tratar da existência ou não de Deus, mas da influência deste na realidade das pessoas que cada vez mais se interessam menos pelos experimentos religiosos, ideais e ritos. O temor de Deus e as festividades

${ }^{8}$ Deus é uma forma de o ser humano expressar-se essencialmente. Mais detalhes a este respeito podem ser encontrados em Chagas et al. (2011).

${ }^{9}$ Para saber mais sobre esse tema consultar Zilles (1991).

\begin{tabular}{|l|l|l|l|l|}
\hline Q & Ano 2 & n. 6 & Janeiro - Agosto 2015 & p. 138-149 \\
\hline
\end{tabular}


religiosas perdem espaço para outros aspectos culturais e os dias santos são comemorados como feriados. O desígnio do homem não é mais controlado por Deus que determina o caminho dos bons e dos maus e responde aos acontecimentos da realidade, pois, as ciências propiciam respostas e confortos que podem ser mais confiáveis do que Deus. O processo de secularização parece enfatizar esse aspecto e a influência de Deus na vida das pessoas está perdendo a sua força ou o seu valor, por isso, se afirma que Deus está morto.

Refletindo sobre as peregrinações de Canindé, percebe-se que tal situação apontada pelo Feuerbach pode ser atribuída ao "santo morto" e não ao "santo vivo". A experiência do santo morto que é contestada pelos peregrinos do santo vivo,encontra-se presente nas práticas das instituições religiosas, sociais e políticas.Por santo morto na instituição religiosa, deve-se compreender a liturgia oficial, credos e dogmas.

Para a Igreja, aperegrinaçãoou festividade religiosa dá-se a partir do santo morto e de tudo o que se relaciona com ele, ou seja, imagens, objetos litúrgicos, liturgia, ritos oficiais. Ela olha aperegrinação de fora para dentro e não de dentro para fora, ou seja, a instituição religiosa não olha o peregrino por dentro, nas suas especificidades, por meio dos seus gestos simbólicos. Ela não vê que o peregrinante expressa memória e identidade, cujo suporte é o seu próprio corpo, pois o corpo é o lugar da cultura e, consequentemente, das subjetividades. Ela não consegue passar da visão superada (Santo morto, imagem) do Sagrado para outra ótica (Santo vivo), diferente da instituição.

Assim, toda e qualquer prática devocional é vista e analisada com um olhar bastante institucional ou profissional. É a prática religiosainstrumental, marcadamente técnica e mecânica, fria e distante da vida das pessoas, dos problemas.

As instituições sociais e políticas que visam o atendimento as necessidades básicas dos peregrinos, como moradia, saúde, educação,mas não cumprem as promessas de campanha ritualizadas a cada eleição, sabem que quanto mais peregrinos carentes existirem na cidade, maior o gasto com verbas e auxílios aos políticos e autoridades competentes. Para tais instituições, a peregrinação ou festividade religiosa acontece como evento propício a pesquisa do mercado turístico.

A partir dessa pesquisa se poderá subsidiar um plano de marketing em parceria com a Igreja para atrair mais peregrinos com a criação de espaços de lazer, esportes e símbolos sagrados como é o caso da estátua de São Francisco no Alto do Moinho, em

\begin{tabular}{|l|l|l|l|l|}
\hline Q Ponista Dialectus & Ano 2 & n. 6 & Janeiro - Agosto 2015 & p. 138-149 \\
\hline
\end{tabular}


Canindé. Todavia, se a execução das promessas eleitoreiras não acontece, os peregrinos do santo vivo seguem seu próprio caminho. Eles não esperam a solução dos problemas a partir das instituições, simbolizadas no santo morto, mas, do santo vivo, conquistada a partir de seus esforços e comunicada nos seus ex-votos em forma de maquetes de casas, partes do corpo, carteira de trabalho. Com tal atitude, questionam a razão de ser e a falta de compromisso dos profissionais de saúde e das instituições.

Portanto, acontece uma mudança para resolver as dificuldades da vida quotidiana, aquilo que é de competência das instituições sociais, passa para a realidade simbólica, função do santo vivo.

Não basta realizar peregrinação, é necessário encarar a presença do mistério. Caso contrário, operegrino, mesmo assíduo nas festividades do padroeiro e praticante de peregrinações, independentemente da religião oficial, se não peregrinar de si para si, ou seja, permanecer dentro de si mesmo, consciente do processo histórico, continua se relacionando com o santo morto, um personagem construto histórico, santo ou eleito de Deus, alguém que morreu e deixou bons exemplos para serem imitados, canonizado ou não pela Igreja oficial. Para o peregrino conquistar sua superação terá que incorporar a experiência do santo vivo e deixar o santo morto.

Ao incorporar o santo vivo o peregrino consegue superar suas dificuldades sem desesperança. Nesse sentido, para libertar-se do sofrimento procura superviver na sua intimidade. Lá onde fracassam as instituições humanas, insurge o mistério. No Santo vivo existemas garantias para salvaguardar a identidade ameaçada pelo novo contexto. O "o que sou" passa a, "em que eu acredito".

A instituição religiosa visa o aspecto espiritual do peregrino. Preocupa-se com a salvação da alma, sacramentos e ritos oficiais. Isto provoca cicatrizes e conquistas que marcam uma sociedade que marcha em busca de um espaço secular, com tensões entre a religião oficial e a devoção popular, inclusive, as peregrinações. Assim, a relação entre ambos é de uma aparente harmonia. A religião oficial com seus ritos e práticas parece reforçar a ideia de que asdificuldades só podem ser resolvidos numa relaçãopessoal com Deus e não pelo esforço do peregrino em comunidade. Esta prática religiosa parece reunir as pessoas para individualizar as dificuldades e se afastarem de sua plena consciência, de suas implicações nos problemas e soluções.

Nesse sentido percebe-se que a crítica de Feuerbach a experiência religiosa é bastante considerável e cabível porque as instituições realizam promessas para o

\begin{tabular}{|l|l|l|l|l|}
\hline Q Ponista Dialectus & Ano 2 & n. 6 & Janeiro - Agosto 2015 & p. 138-149 \\
\hline
\end{tabular}


futuro,refletem uma realidade fora do mundo vivido do peregrino, dos seus anseios e vontades, ou seja, distante da vida.

Contudo, na prática do "santo vivo" que independe das instituições e que é o resultado da construção do próprio homem que busca ressignificar e conquistar seu espaço,notamos que pode haver uma possibilidade de diálogo dialético, porque as realizações e conquistas dos peregrinos não são projetadas para o futuro ou para as instituições, mas conquistadas a partir do cotidiano do peregrino e os seus resultados são apresentados e testemunhados nos ex-votos depositados anualmente nos santuários. Os peregrinos querem salvar seus corpos sofridos e não seu "corpo espiritual" e integramse numa profunda peregrinação de resgate da subjetividade.

\section{Referências}

CASTRO, Márcia Moura. Ex-votos Mineiros. As tábuas votivas no ciclo do ouro. Rio de janeiro: Expressão e Cultura, 1994.

CHAGAS, Eduardo F.; REDYSON, Deyve (Orgs.). Ludwig Feuerbach: Filosofia, Religião e Natureza. São Leopoldo: Editora Nova Harmonia, 2011.

FEUERBACH. Ludwig. A essência do cristianismo. Campinas: Papirus, 1988.

LIBÂNIO, J.B. Utopia e Esperança Cristã, São Paulo: Loyola, 1989.

OLIVEIRA, José Cláudio Alves de. Semiologia dos ex-votos na Bahia: arte, simbolismo e comunicação religiosa. In: Revista Internacional de Folkcomunicação, VOL. 5, n. 9. 2007.

, Marcelo João Soares de. O Símbolo e o Ex-Voto em Canindé. In: Revista de Estudos da Religião. São Paulo: PUC, No 3 /2003.

RUSCHEINSKY, Aloísio. A presença do simbólico, São Paulo: PUC, 1988.

SCARANO, Julita. Fé e Milagre: Ex-votos pintados em madeira, séculos XVIII e XIX. São Paulo: Edusp, 2004.

SILVA, Maria Augusta Machado da. Ex-votos e orantes no Brasil. Rio de Janeiro: Museu Históricos Nacional, 1981.

ZILLES, Urbano. Filosofia da Religião, 5ª ed., São Paulo, Paulus, 1991.

\begin{tabular}{|l|l|l|l|l|}
\hline Q Rovista Dialectus & Ano 2 & n. 6 & Janeiro - Agosto 2015 & p. 138-149 \\
\hline
\end{tabular}

